\title{
Formation of phosphatidylethanol from endogenous phosphatidylcholines in animal tissues from pig, calf, and goat
}

\author{
Authors: \\ Marc Luginbühl ${ }^{1}$, Sytske Willem², Stefan Schürch ${ }^{3}$, Wolfgang Weinmann ${ }^{1}$ \\ $1^{\text {st }}$ author orcid: 0000-0002-3111-0750 \\ Last author orcid: 0000-0001-8659-1304 \\ Affiliations: \\ ${ }^{1}$ Institute of Forensic Medicine, University of Bern, Switzerland \\ ${ }^{2}$ Laboratory of Toxicology, University of Ghent, Belgium \\ ${ }^{3}$ Department of Chemistry and Biochemistry, University of Bern, Switzerland \\ Addresses: \\ ${ }^{1}$ Institute of Forensic Medicine, University of Bern \\ Bühlstrasse 20 \\ 3012 Bern \\ Switzerland \\ ${ }^{2}$ Laboratory of Toxicology, University of Ghent \\ FFW - 4th Floor \\ Ottergemsesteenweg 460 \\ 9000 Gent \\ Belgium \\ ${ }^{3}$ Department of Chemistry and Biochemistry, University of Bern \\ Freiestrasse 3 \\ 3012 Bern \\ Switzerland \\ Corresponding author: \\ Wolfgang Weinmann \\ Institute of Forensic Medicine, University of Bern \\ Bühlstrasse 20 \\ 3012 Bern \\ Switzerland \\ Email: wolfgang.weinmann@irm.unibe.ch
}




\begin{abstract}
In the presence of alcohol, phosphatidylcholine (PC) is transformed to the direct alcohol biomarker phosphatidylethanol (PEth). This reaction is catalyzed by the enzyme phospholipase D (PLD) and dependent upon substrate availability. As recent methods have solely focused on the determination of PEth, information about the PC composition was generally missing. To address this issue and monitor PC (16:0/18:1 and 16:0/18:2) and PEth (16:0/18:1 and 16:0/18:2) simultaneously, a reversed phase LC-MS/MS method based on a C8 core-shell column, coupled to a Sciex 5500 QTrap instrument was developed. By application of polarity switching, at first, PC was measured in ESI positive SRM mode, while PEth was determined at a later stage in ESI negative SRM mode. The PEth method was validated for human blood samples to show its robustness and subsequently applied for the investigation of systematic in-vitro PEth formation in animal tissue samples (brain, kidney, liver, and blood) from a pig, a calf, and a goat. Homogenized tissue was incubated at $37^{\circ} \mathrm{C}$ with varying ethanol concentrations from 1-7 $\mathrm{g} / \mathrm{kg}$ (determined by HS-GC-FID) for five hours, whereby a sample was taken every 30 minutes. For all tissue samples, an increase in PEth was measurable. PEth concentrations formed in blood remained below the LLOQ, in agreement with literature. Data analysis of Michaelis-Menten kinetics and PC within the tissue provided a detailed insight about PEth formation, as the occurrence of PEth species can be linked to the observed PC composition. The results of this study show that PEth formation rates vary from tissue to tissue and among different species. Furthermore, new recommendations for PEth analysis are presented.
\end{abstract}

\title{
Keywords
}

phosphatidylethanol, phosphatidylcholine, alcohol biomarker, LC-MS/MS, abstinence monitoring

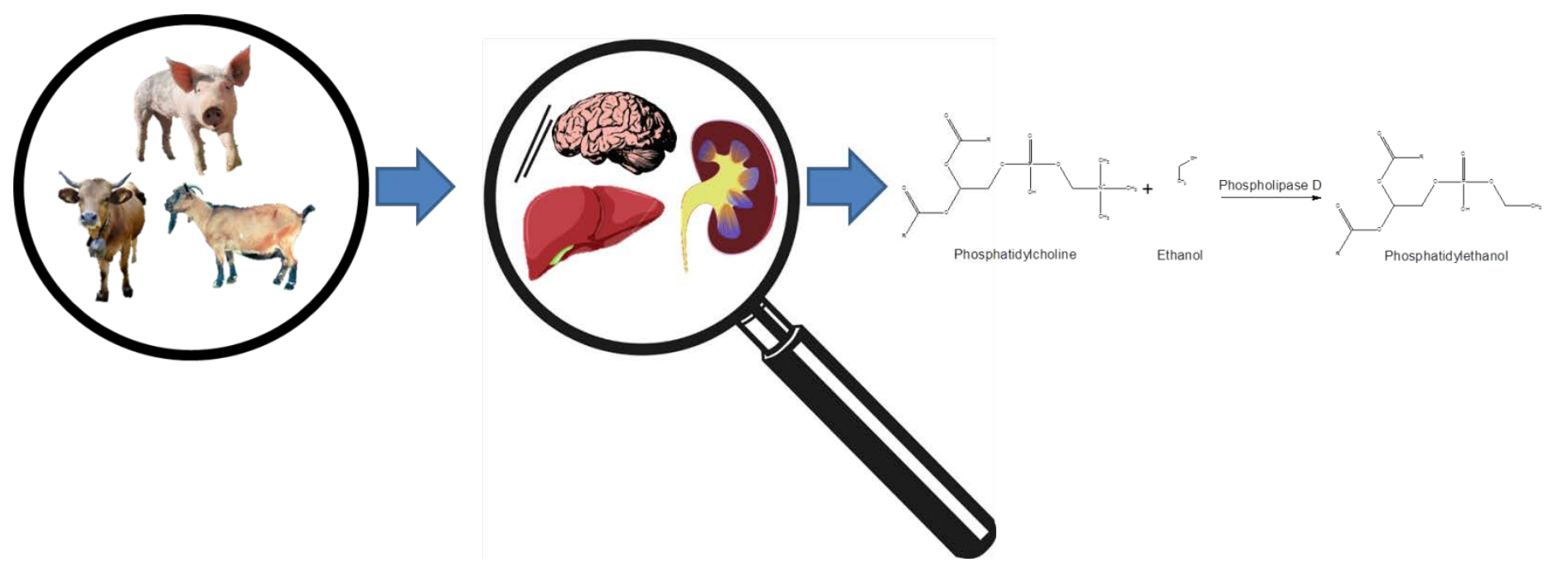

Figure 1Graphical Abstract 


\section{Introduction}

As alcohol is one of the most abused substances worldwide, the investigation of consumption behavior by analyzing direct alcohol biomarkers has gained vast popularity (1). The analysis is performed during driving aptitude assessments (after driving under the influence of alcohol), in child custody cases where one of the parents is suspected of alcohol abuse, and to answer various forensic questions, e.g. post-mortem analysis. In comparison to state markers (generally used for the assessment of heavy drinking) such as carbohydrate-deficient transferrin (CDT), gamma-glutamyl transferase ( $\gamma$-GT) or the measurement of the mean corpuscular erythrocyte volume (MCV), direct alcohol markers have a higher selectivity and specificity (2). By investigation of direct alcohol markers within different matrices, evidence of both, short- and long-term consumption can be obtained for high and low doses of alcohol. The most promising direct alcohol biomarker to monitor regular alcohol consumption was found in phosphatidylethanol (PEth), as the pharmacokinetic characteristics provide a long detection window when compared to other direct alcohol biomarkers such as ethyl glucuronide, ethyl sulfate, fatty acid ethyl esters or $\mathrm{N}$-acetyltaurine (3-7). Unlike hair analysis, which is generally used for the assessment of drinking behavior over a longer time period, PEth determination in blood or organ tissue can serve as an intermediary long term marker without being subject to washout effects (8-10). However, a not insignificant drawback for PEth analysis is the instability against oxidation and hydrolysis, demanding a short turnover between sampling and analysis (11).

The phospholipid PEth is formed in the presence of ethanol, by modification of phosphatidylcholine (PC), catalyzed by phospholipase D (PLD) (12). Based on the PC substrate availability, PEth 16:0/18:1 and PEth 16:0/18:2 are the predominant PEth species generally found in blood and frequently monitored together for abstinence monitoring (1). Considering the quantitative analysis of diacyl-glycerophospholipids, Lehmann et al. recently stated that different structural isomers of phosphatidylcholine 18:1/18:0 and 18:0/18:1 cause a slightly different fragmentation pattern when monitoring the fatty acid chains (13). This is caused by the fact that fragmentation at the SN2 position is preferred, which results in a higher signal for the fatty acid chain being present at this position. Therefore special attention has to be paid when analyzing PC or PEth samples within various tissues. Dependent on the exact composition of the investigated matrix, significant differences between the diacyl-glycerophospholipid concentrations (PC and PEth) determined with the quantifier (SRM1) compared to quantification by the use of the qualifier (SRM2) are likely to occur (if the transitions are including the fatty acid chain). This is based on the fact that the commercially available PC and PEth used for the calibration and the PC and PEth present in the investigated tissue do not necessarily contain the same composition of structural isomers.

In this study, we investigated the in-vitro formation of PEth in the brain, kidney, and liver from a pig, a calf, and a goat by systematic incubation with ethanol concentrations from $1-7 \mathrm{~g} / \mathrm{kg}$. The goal of the study was to propose and demonstrate a procedure to gain a detailed insight into PEth formation in organ tissue. This procedure presents an advanced application of the in-vitro incubation to investigate PLD activity, on the base of the study from Schröck et al., which focused on PEth formation in human blood (14). The execution of the proposed in-vitro study permits the investigation of PEth formation with respect to the presence of both substrates involved in PEth formation, PC and ethanol. It may help to explain the high variability of PEth concentrations and compositions observed when measuring different tissue samples from post mortem cases (10). It is known, that the PC composition may vary with the diet or within different tissues (15-17), however detailed research about PEth formation has been missing so far. Kinetic assessments investigating the potential of PEth formation within animal tissue could furthermore provide an alternative to in-vivo animal studies, where animals are fed with an alcohol solution for several days and sacrificed afterwards $(18,19)$. 


\section{Materials and methods}

\section{Reagents}

Acetonitrile, p.a., was purchased from Acros Organics (Geel, Belgium), isopropyl alcohol, HPLC grade, was obtained from Fisher Chemical (Reinach, Switzerland). Phosphatidylcholine 16:0/18:1, 16:0/18:2, and 16:0/18:1- $d_{31}$ were purchased from Avanti Polar Lipids, Inc. (Alabaster, USA). Certified spiking solution for phosphatidylethanol 16:0/18:1 and 16:0/18:2 were purchased from Cerilliant (Round Rock, USA). No information on structural isomers was provided by the company. Formic acid, puriss p.a. $98 \%$, phospholipase D from cabbage, and ethanol- $d_{6}(\geq 99.5$ atom \% D) were purchased from Sigma-Aldrich (Buchs, Switzerland). De-ionized water was produced with a MilliQ water system from Millipore (Billerica, USA). Ammonium acetate, diethyl ether, calcium chloride, sodium chloride, and chloroform were obtained from Merck (Darmstadt, Germany).

\section{Synthesis of internal standard}

The deuterated internal standards for PEth, 16:0/18:1- $d_{5}$ and PEth 16:0/18:2- $d_{5}$, were synthesized as described previously (20). Briefly, $10 \mathrm{mg}$ of each PC, 16:0/18:1 and 16:0/18:2, were dissolved in $1.5 \mathrm{~mL}$ diethyl ether in individual glass vials together with $200 \mu \mathrm{L}$ ethanol- $d_{6}(\geq 99.5$ atom \% D), $200 \mu \mathrm{g}$ of phospholipase D, and $2.25 \mathrm{~mL}$ of water containing $100 \mathrm{mM}$ calcium chloride and $100 \mathrm{mM}$ ammonium acetate. The mixtures were shaken for six hours at room temperature and stored in the fridge overnight, where phase separation took place. Then the organic phase was transferred to a $6 \mathrm{~mL}$ glass vial. The remaining aqueous phase was extracted with $1.5 \mathrm{~mL}$ diethyl ether three times. All the organic phases were collected and evaporated under a stream of nitrogen at $50^{\circ} \mathrm{C}$. The white residue was dissolved in a $5 \mathrm{~mL}$ chloroform/methanol (5:8 v/v) mixture and filtered. The solvent was evaporated subsequently. The residue was dissolved in $1 \mathrm{~mL}$ chloroform and stored in individual $2 \mathrm{~mL}$ crimp-top vials in the freezer at about $-20^{\circ} \mathrm{C}$. For the final PEth internal standard solution $5 \mu \mathrm{L}$ PEth 16:0/18:2- $\mathrm{d}_{5}$ and $6.6 \mu \mathrm{L}$ PEth 16:0/18:1- $\mathrm{d}_{5}$ stock solution were evaporated and reconstituted in $15 \mathrm{~mL}$ 2-propanol. To avoid sample contamination with remaining educt (PC), the internal standard mixture was tested for remains of PC, by the injection of a concentrated internal standard solution into the LC-MS/MS system. With respect to the monitored MRM transitions for the specific PC educts, no interfering signals could be detected. Remaining PC residues in the internal standard solution would interfere with the simultaneous PC determination in animal tissue since the PC analogs used to prepare the PEth IS are identical to the ones determined in animal tissue.

\section{In-vitro study design}

Animal tissue samples (brain (cerebral cortex), liver, and kidney) from a pig (female, $100 \mathrm{~kg}$, domestic pig, selectively bred for meat production by crossing with Duroc pig), a calf (170 kg, male, castrated) and a goat (10 kg) were obtained freshly from the butcher (Schlieren, Switzerland) on days of slaughtering. In addition, blood from a calf and pooled blood from pigs $(n=9)$ were collected in $9 \mathrm{~mL}$ S-monovette tubes containing lithium heparinate to prevent coagulation (Sarstedt, Nümbrecht, Germany). Blood from the goat was not available. Approximately 3.5 g of tissue sample was weighed into each homogenization tube $(n=8)$ (gentleMacs M Tubes, Macs Miltenyi Biotec, Bergisch Gladbach, Germany). Afterwards, $2.5 \mathrm{~mL}$ sodium chloride solution (150 mM) was added per gram of tissue sample, before homogenization by using a pre-programmed 45 seconds gradient took place (gentle Macs Dissociator). Blood samples were used without any dilution (about $7 \mathrm{~mL}$ in plastic tubes $(13 \mathrm{~mL}, 100 \times 16 \mathrm{~mm}$, Sarstedt, Nümbrecht, Germany)). After one hour in an incubator (Binder, Tuttlingen, Germany) at $37{ }^{\circ} \mathrm{C}$, each sample tube (except for the negative control) was spiked with pure ethanol to start the formation of PEth. This resulted in alcohol concentrations of about 1, 2, 3, 4, 5, 6 and $7 \mathrm{~g} / \mathrm{kg}$ (accounting for the total weight of the tissue and the solvent, exact ethanol concentrations were determined by HS-GC-FID). The range of spiked alcohol concentrations was chosen with respect to the $\mathrm{LD}_{50}$ for rats at $7 \mathrm{~g} / \mathrm{kg}$. Samples were subsequently incubated at $37^{\circ} \mathrm{C}$. Diluted, homogenized tissue sample ( $175 \mu \mathrm{L}$, accounting for $50 \mathrm{mg}$ of tissue) or $250 \mu \mathrm{L}$ of blood were taken every 30 minutes during 5 hours by addition to $2 \mathrm{~mL}$ Eppendorf tubes containing $1 \mathrm{~mL}$ of acetonitrile each. Prior to every sampling, the sample tubes were shaken and vortexed for about 10 seconds (vortex genie, scientific industries, New 
York, USA). In order to quantify PEth, individual calibration samples were prepared in each of the investigated matrices and, for external control and PC determination, additionally in solvent. To investigate matrix effects, extraction efficiency, and recovery, tissue samples were spiked with PEth at a low $(0.15 \mu \mathrm{g} / \mathrm{g})$ and high $(1.5 \mu \mathrm{g} / \mathrm{g})$ concentration ( $\mathrm{n}=3$ ), see Table 6 (supplementary data) (21).

\section{Determination of alcohol concentration}

After the addition of a previously calculated amount of alcohol from 1 to $7 \mathrm{~g} / \mathrm{kg}$, the homogenized animal tissue samples from brain, liver, kidney, and blood were analyzed for their individual alcohol concentrations by using headspace gas chromatography coupled to a flame ionization detector (HS-GC-FID). Prior to the analysis, the samples were diluted by adding water $(1: 1, w / w)$ to keep the alcohol concentrations within the calibration range. This step was performed by measuring the weight of both added solutions with an analytical balance (AT200, Mettler Toledo, Bern, Switzerland). Following this step, the samples were analyzed by using two individual GC-FID systems (HP 6890 Series) equipped with two different GC-columns. Each sample was analyzed in duplicate on each system (4 measurements in total by using about $110 \mathrm{mg}$ of the sample for each determination), analogously to BAC determination in serum, as required by Swiss regulations for forensic BAC determinations (22). Finally, a retrograde calculation accounting for the dilution led to the final alcohol concentration.

\section{Sample preparation for LC-MS/MS measurements}

Protein precipitation, in order to stop any PEth formation after sampling, was performed by adding $1 \mathrm{~mL}$ acetonitrile to the individual tissue sample ( $50 \mathrm{mg}$ of tissue), followed by ten seconds of vortexing, see the section in-vitro study design. For the subsequent extraction of PEth and PC, $300 \mu \mathrm{L}$ isopropyl alcohol and $10 \mu \mathrm{L}$ internal standard solution (PEth 16:0/18:1- $d_{5}$, PEth 16:0/18:2- $d_{5}$ and PC 16:0/18:1- $d_{31}$ ) were added, before the sample was shaken vigorously for ten minutes (VXR Vibrax shaker, IKA, Staufen, Germany). Following this step, the samples were centrifuged for ten minutes at 16,000 $\mathrm{g}$ (Mikro 220R, Hettich, Bäch, Switzerland) before the supernatant was transferred into a 1.5 $\mathrm{mL}$ standard snap-crimp autosampler glass vial and evaporated to dryness under a gentle stream of nitrogen at $50{ }^{\circ} \mathrm{C}$. The residue was reconstituted in $400 \mu \mathrm{L}$ acetonitile/2-propanol/ $\mathrm{H}_{2} \mathrm{O}(42: 40: 18, \mathrm{v} / \mathrm{v})$ and injected into the LC-MS/MS system. In order to remain within the calibration range for phosphatidylcholine (which varies between the different tissues), different amounts of animal tissue were extracted additionally (25 mg, $12.5 \mathrm{mg}$, and $6.3 \mathrm{mg}$, and due to the high PC content, for brain additionally $2.85 \mathrm{mg}$ and $1.43 \mathrm{mg}$ ). 


\section{LC-MS/MS analysis for phosphatidylcholine and phosphatidylethanol}

The concentration of the main PEth precursor molecules, PC 16:0/18:1 and PC 16:0/18:2, and the two most abundant analogs of phosphatidylethanol, PEth 16:0/18:1 and PEth 16:0/18:2, were determined by liquid chromatography, tandem mass spectrometry (LC-MS/MS) by using the same method for all the analytes, see Figure 2. In order to obtain a chromatographic separation, a reversed phase Kinetex core-shell C8 column, 2.6 m, $100 \AA$, 100 x $2.1 \mathrm{~mm}$ (Phenomenex, Torrance, USA), on an UltiMate ${ }^{\circledR} 3000$ UHPLC system (Dionex, Thermo Scientific Instruments, Reinach, Switzerland) was used. The analytes were separated with a flow rate of $0.3 \mathrm{~mL} / \mathrm{min}$ at $60{ }^{\circ} \mathrm{C}$ (reaching an operating pressure of about 180-300 bar). Gradient elution was performed with 70:30 (v/v) acetonitrile/water with 0.1\% formic acid (A) and pure isopropyl alcohol (B): 0-1 min: $40 \%$ B; 1-7 min: $40 \%$ B to $80 \%$ B; $7.1-8.5$ min $99 \%$ B; 8.5-10 min $40 \%$ B. By using the six port valve system of the LC system, the flow was directed into the waste during the first 4 minutes to minimize potential contamination of the mass spectrometer (5500 QTRAP, Sciex, Toronto, Canada). Afterwards, the valve was switched to direct the flow to the mass spectrometer, which was operated in electrospray positive mode with selected reaction monitoring (SRM) for PC determination: ion spray voltage at $2000 \mathrm{~V}$, source temperature of $500{ }^{\circ} \mathrm{C}$, collision gas at medium, curtain gas at 30, gas 1 at 15 , gas 2 at 20, and a cycle time of $0.200 \mathrm{~s}$ (arbitrary units). After 5.85 minutes the mass spectrometer was switched to the electrospray negative mode for the determination of PEth: ion spray voltage at $-4250 \mathrm{~V}$, source temperature of 500 ${ }^{\circ} \mathrm{C}$, collision gas at medium, curtain gas at 30, gas 1 at 15, gas 2 at 20, and a cycle time of $0.2501 \mathrm{~s}$ (arbitrary units). For MS/MS parameters, see Table 1.

Table 1.- Mass spectrometric parameters and retention times for phosphatidylcholine and phosphatidylethanol determination. $\mathrm{Q} 1=$ parent ion, $\mathrm{Q} 3=$ fragment ion, $\mathrm{DP}=$ declustering potential, $\mathrm{CE}=$ collision energy, $\mathrm{CXP}=$ cell exit potential, $\mathrm{RT}=$ retention times.

\begin{tabular}{|c|c|c|c|c|c|c|c|}
\hline Compound & $\begin{array}{c}\text { Q1 } \\
{[\mathrm{m} / \mathrm{z}]}\end{array}$ & $\begin{array}{c}\text { Q3 } \\
{[\mathrm{m} / \mathrm{z}]}\end{array}$ & $\begin{array}{c}\text { Dwell time } \\
\text { [msec] }\end{array}$ & $\begin{array}{c}\text { DP } \\
\text { [volts] }\end{array}$ & $\begin{array}{c}\text { CE } \\
\text { [volts] }\end{array}$ & $\begin{array}{c}\text { CXP } \\
\text { [volts] }\end{array}$ & $\begin{array}{c}\mathrm{RT} \\
\text { [min] }\end{array}$ \\
\hline PC 16:0/18:1 SRM1 & 760.6 & 124.8 & 20 & 14 & 111 & 7 & \multirow{2}{*}{5.72} \\
\hline PC 16:0/18:1 SRM2 & 760.6 & 184.1 & 20 & 11 & 37 & 11 & \\
\hline PC $16: 0 / 18: 1-d_{31}$ SRM1 & 791.7 & 184.1 & 20 & 5 & 45 & 42 & \multirow{2}{*}{5.63} \\
\hline PC 16:0/18:1- $d_{31}$ SRM2 & 791.7 & 791.7 & 20 & 7 & 15 & 40 & \\
\hline PC 16:0/18:2 SRM1 & 758.3 & 125.3 & 20 & 10 & 94 & 9 & \multirow{2}{*}{5.46} \\
\hline PC 16:0/18:2 SRM2 & 758.3 & 184.1 & 20 & 10 & 40 & 9 & \\
\hline \multicolumn{8}{|c|}{ polarity switch from $2000 \mathrm{~V}$ to $-4250 \mathrm{~V}$ at 5.85 minutes } \\
\hline PEth 16:0/18:1 SRM1 & 701.3 & 255.2 & 20 & -32 & -40 & -14 & \multirow{2}{*}{6.36} \\
\hline PEth 16:0/18:1 SRM2 & 701.3 & 281.3 & 20 & -20 & -40 & -14 & \\
\hline PEth 16:0/18:1- $d_{5}$ SRM1 & 706.3 & 255.3 & 20 & -20 & -40 & -14 & \multirow{2}{*}{6.34} \\
\hline PEth 16:0/18:1- $d_{5}$ SRM2 & 706.3 & 281.1 & 20 & -32 & -40 & -14 & \\
\hline PEth 16:0/18:2 SRM1 & 699.5 & 279.4 & 20 & -5 & -40 & -14 & \multirow{2}{*}{6.10} \\
\hline PEth 16:0/18:2 SRM2 & 699.5 & 255.3 & 20 & -5 & -40 & -14 & \\
\hline PEth 16:0/18:2- $d_{5}$ SRM1 & 704.5 & 279.5 & 20 & -5 & -40 & -14 & \multirow{2}{*}{6.08} \\
\hline PEth 16:0/18:2- $d_{5}$ SRM2 & 704.5 & 255.3 & 20 & -5 & -40 & -14 & \\
\hline
\end{tabular}


a.)

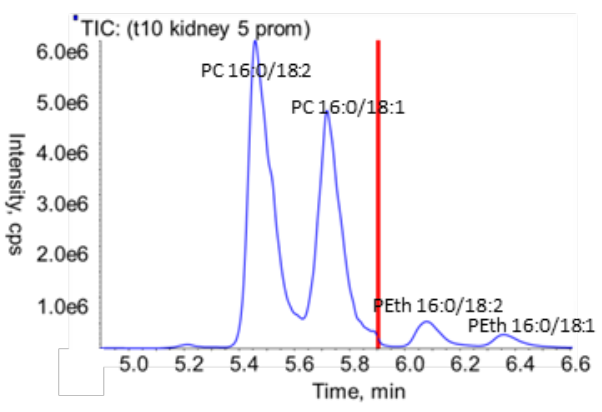

b.)

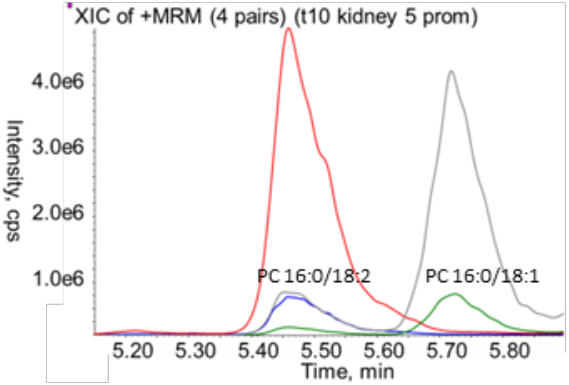

c.)

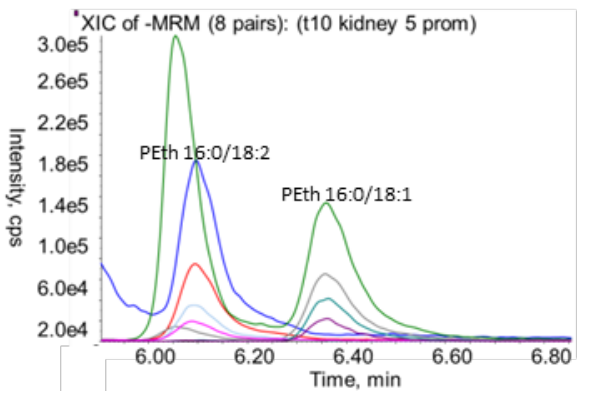

Figure 2 Detailed chromatograms for PC and PEth determination within kidney tissue, spiked with 5 g/kg of ethanol.

a.) total ion chromatogram for a kidney sample, the polarity switch at $\mathbf{5 . 8 5} \mathbf{m i n}$ is indicated with a bar.

b.) extracted ion chromatogram for PC 16:0/18:2 $(758.3 \rightarrow 125.3$ blue, $758.3 \rightarrow 184.1$ red) and PC 16:0/18:1 $(760.6 \rightarrow 124.8$ green, $760.6 \rightarrow 184.1$ grey).

c.) extracted ion chromatogram for PEth 16:0/18:2 (699.5 $\rightarrow 279.4$ blue, $699.5 \rightarrow 255.3$ red) and PEth 16:0/18:1 $(701.3 \rightarrow 281.3$ green, $701.3 \rightarrow 255.2$ grey) with the respective internal standard $(704.5 \rightarrow 279.5$ light blue, $704.5 \rightarrow 255.3$ pink, $706.3 \rightarrow 281.1$ mint, $706.3 \rightarrow 255.3$ purple) 


\section{Data processing for phosphatidylcholine and phosphatidylethanol determination}

Phosphatidylethanol concentrations were corrected for the amount of PEth 16:0/18:1 (74.4\%) and PEth 16:0/18:2 (74.2\%) within the certified spiking solution from Cerilliant, which was delivered as tetra-N-butylammonium salt. Ionization differences and losses during sample preparation were corrected by the addition of the respective internal standards, PEth 16:0/18:1- $d_{5}$ and PEth 16:0/18:2- $d_{5}$, by dividing the area of the analyte signal by the area of the respective internal standard signal. For the quantification of phosphatidylcholine only one internal standard, PC 16:0/18:1- $d_{31}$, was used for both analytes (the use of the initially intended PC 17:0/17:0 proved to be unsuitable due to interferences). The mean of the concentrations determined with the two monitored SRM transitions, representing different fatty acids as product ions: $\mathrm{m} / \mathrm{z} 255.2$ for the palmitate (16:0), 281.3 for the oleate (18:1), and 279.4 for the linoleate (18:2), was taken into account for different positional isomers of PEth. The ratios of the product ion intensities vary slightly, depending on the distribution of the fatty acid chains at the SN1 or SN2 position. Chromatographic baseline separation of these positional isomers is not possible. We investigated quantification differences between SRM1 and SRM2 in samples from organ tissues, (PEth 16:0/18:1 vs. PEth 18:1/16:0 and PEth 16:0/18:2 vs. PEth 18:2/16:0) however, not in spiked samples (as the ratio within the reference solution remains constant). To normalize these differences to the reference solution, we decided to report the mean concentration of both transitions as final concentration throughout the manuscript. However, the exact distribution within the reference solution remains unknown. Experimental details about the occurrence of this issue are provided in the results and discussion section. For the quantification of PCs, where fragment ions containing the polar head group were monitored, we agreed to report the mean of both transitions as well.

\section{Phosphatidylcholine and phosphatidylethanol method validation}

PC concentrations were determined by using a seven-point calibration $(0.5-100 \mu \mathrm{g} / \mathrm{mL})$ and three quality control samples $(1,3,75 \mu \mathrm{g} / \mathrm{mL})$ in solvent. The LLOQ was set at $1 \mu \mathrm{g} / \mathrm{mL}$, the LOD at $0.2 \mu \mathrm{g} / \mathrm{mL}$. PEth concentrations were determined with a seven-point calibration $(0.0075-1.5 \mu \mathrm{g} / \mathrm{mL})$ and four quality control samples $(0.0075,0.015$, $0.045,1,125 \mu \mathrm{g} / \mathrm{mL}$ ) prepared in blood from an abstinent subject ( $250 \mu \mathrm{L}$ of blood, no PEth detectable). The LLOQ was set at $0.0075 \mu \mathrm{g} / \mathrm{mL}$, the LOD at $0.0035 \mu \mathrm{g} / \mathrm{mL}$. Sample preparation was performed as described in the section sample preparation for LC-MS/MS measurements. For method validation, three series of six samples at each quality control concentration were prepared and analyzed on three different days by using two calibration series, according to FDA guidelines (23). According to these guidelines, the mean value for accuracy and imprecision for quality control samples ( $\mathrm{n}=6$ ), during each series (intra-assay) and among three series (inter-assay) has to be within $\pm 15 \%$ of the actual value, except at the limit of quantification (LLOQ), where a deviation up to $\pm 20 \%$ is accepted. Extraction efficiency, recovery, and matrix effects were investigated quantitatively (in triplicate) according to Matuszewski for each tissue sample at a low and a high concentration $(0.04 \mu \mathrm{g} / \mathrm{mL}$ and $0.5 \mu \mathrm{g} / \mathrm{mL})$. (21). The recovery, extraction efficiency, and matrix effect for PC could not be investigated, as PC represents an endogenous substance which is present in high concentrations in blood. However, by performing series of dilution for each tissue, no significant effect considering concentration differences could be observed. For blood samples, an amount of $2 \mu \mathrm{L}$ was injected. For calibration samples in solvent, $0.4 \mu \mathrm{L}$ was injected into the LC-MS system.

\section{Isomer specific fragment ion abundances of PEth}

In order to show the effect of isomer specific fragmentation occurring for diacyl-glycerophospholipids such as PEth, when monitoring acyl fragments, the individual concentrations of PEth, obtained from the two monitored SRM transitions (>LLOQ), were compared by the mean observed concentration. Therefore the concentration determined with the SRM transition which monitors SRM1 (product ion with $\mathrm{m} / \mathrm{z} 255$ (palmitate (16:0)) was divided by the quantitative result with SRM 2 (product ion with m/z 281.3 (oleate (18:1)) or 279.4 (linoleate (18:2))). 


\section{Results and Discussion}

\section{Validation Results for PC and PEth}

During method validation, the observed calibration linearity was $>0.9968$ for PC 16:0/18:1 and $>0.9956$ for PC 16:0/18:2, by using a weighted calibration $(1 / \mathrm{x})$. Intra-assay accuracy and precision, determined by measuring six samples of each quality control sample (series 1) were determined to be $93-105 \%$ and $1.8-4.0 \% \mathrm{CV}$ for PC 16:0/18:1, and 95-111\% and 2.1-7.5 \%CV for PC 16:0/18:2, respectively. Inter-assay accuracy and precision for three series with six measurements in each series $(\mathrm{n}=18)$ were $95.6-104.4 \%$ and 3.2-4.7 \%CV for PC 16:0/18:1, and 99.2-108.6\% and 4.8-7.0 \%CV for PC 16:0/18:2, respectively.

The observed calibration linearity during method validation was $>0.9981$ for PEth 16:0/18:1, and $>0.9983$ for PEth 16:0/18:2, by using a weighted calibration (1/x). Intra-assay accuracy and precision (series 1 ), determined by measuring six samples of each quality control sample were determined to be 93-107\% and 3.1-8.9 \%CV for PEth 16:0/18:1, and 91-111\% and 4.4-8.0 \%CV for PEth 16:0/18:2, respectively. Inter-assay accuracy and precision for three series with six measurements in each series $(\mathrm{n}=18)$ were $95.9-102.8 \%$ and 4.2-7.2 \%CV for PEth 16:0/18:1, and 94.8-109.8\% and 4.2-6.9 \%CV for PEth 16:0/18:2, respectively. The observed matrix effects for PEth are presented in Table 2. With respect to the obtained validation data for PC and PEth, the method fulfills the criteria for accuracy and precision of the FDA guidelines.

Table 2 Recovery, extraction efficiency, and matrix effects for blood samples spiked with a low and a high concentration of PEth $(0.04 \mu \mathrm{g} / \mathrm{mL}$ and $0.5 \mu \mathrm{g} / \mathrm{mL})$. The data represents the mean of SRM1 and SRM2, by taking the mean out of three measurements at each concentration, in each tissue.

\begin{tabular}{|l|c|c|c|c|}
\hline & $\mathbf{1 6 : 0 / 1 8 : 1 ~ l o w ~}$ & $\mathbf{1 6 : 0 / 1 8 : 1 ~ h i g h ~}$ & $\mathbf{1 6 : 0 / 1 8 : 2 ~ l o w ~}$ & $\mathbf{1 6 : 0 / 1 8 : 2 ~ h i g h ~}$ \\
\hline recovery & $77 \%$ & $74 \%$ & $80 \%$ & $79 \%$ \\
\hline extraction efficiency & $75 \%$ & $80 \%$ & $78 \%$ & $91 \%$ \\
\hline matrix effects & $102 \%$ & $93 \%$ & $102 \%$ & $88 \%$ \\
\hline
\end{tabular}




\section{PC concentration in tissue samples}

\section{Brain}

From all tissue samples, the brain tissue showed the highest phosphatidylcholine concentrations for the investigated PCs, being responsible for $11.5 \%$ (calf) and $13.0 \%$ (goat \& pig) of the total brain mass (moist mass). In order to be within the PC calibration range, low amounts of the sample had to be measured by using just $1.43 \mathrm{mg}$ or $2.85 \mathrm{mg}$ of homogenized tissue. A comparison between PC 16:0/18:1 and PC 16:0/18:2 showed that PC 16:0/18:2 accounts for only $3.95 \%$ (pig), $4.31 \%$ (calf), and $4.95 \%$ (goat) of the total mass of both substances. This results in a narrow ratio for all the species for PC 16:0/18:2 to PC 16:0/18:1 of 4.1-5.2\%, indicating that PC 16:0/18:1 is the main substrate for PEth formation in the brain. For a detailed comparison refer to Table 3.

\section{Liver}

Among the three tested species, the liver tissue showed the highest variability in phosphatidylcholine concentrations. The measured PC concentrations accounted for 5.0\% (calf), 6.0\% (goat), and 8.6\% (pig) of the total tissue mass. The observed amounts for PC 16:0/18:1 were 3.5\% (calf), 4.1\% (goat), and 4.9\% (pig). PC 16:0/18:2 was responsible for a share of $1.4 \%$ (calf), $1.9 \%$ (goat), and 3.8\% (pig). This results in a ratio of PC 16:0/18:2 to PC 16:0/18:1 of 40$78 \%$. For the calf, the liver was the organ with the lowest amount of total PC. For a detailed comparison refer to Table 3.

\section{Kidney}

PC 16:0/18:1 and PC 16:0/18:2 concentrations in kidney were responsible for 5.2\% (goat), 6.0\% (calf), and 6.3\% (pig) of the total mass. Among the three observed organs, the kidney showed the lowest amount of phosphatidylcholine for the pig and the goat. The observed amount of PC 16:0/18:1 within the kidney was close to each other, by accounting for 3.4\% (pig), 3.5\% (goat) and 3.6\% (calf) of the total mass. The percentage of PC 16:0/18:2 however, showed a higher variability, being responsible for $1.7 \%$ (goat), $2.3 \%$ (calf), and $2.9 \%$ of the total mass. This results in a ratio of PC 16:0/18:2 to PC 16:0/18:1 of 48-85\%. For a detailed comparison refer to Table 3.

\section{Blood}

The investigated blood samples from pig and calf showed the lowest amount of PC by weight when compared to organ tissue. Pig blood showed almost equivalent amounts of PC 16:0/18:1 and PC 16:0/18:2 at 89 $\mu \mathrm{g} / \mathrm{mL}$ and 81.5 $\mu \mathrm{g} / \mathrm{mL}$, respectively. This accounts for $0.009 \%$ and $0.008 \%$ of the total weight. In the blood of the calf, concentrations of $28 \mu \mathrm{g} / \mathrm{mL}$ for PC 16:0/18:1 and $102 \mu \mathrm{g} / \mathrm{mL}$ for PC 16:0/18:2 were measured, resulting in a ratio of PC 16:0/18:2 to PC 16:0/18:1 of $356 \%$.

Table 3 Percentage of measured PC concentration within the sample for PC 16:0/18:1, PC16:0/18:2 and the sum (total mass) of both PC concentrations. Figures displayed here are rounded.

\begin{tabular}{|l|l|c|c|c|c|}
\hline \multicolumn{2}{|c|}{} & PC 16:0/18:1 & PC 16:0/18:2 & total mass & $\begin{array}{c}\text { Ratio } \\
(16: 0 / 18: 2) /(16: 0 / 18: 1)\end{array}$ \\
\hline \multirow{4}{*}{ Pig } & Brain & $12.5 \%$ & $0.5 \%$ & $13.0 \%$ & $4.1 \%$ \\
\cline { 2 - 6 } & Kidney & $3.4 \%$ & $2.9 \%$ & $6.3 \%$ & $85.5 \%$ \\
\cline { 2 - 6 } & Liver & $4.9 \%$ & $3.8 \%$ & $8.6 \%$ & $77.5 \%$ \\
\hline \multirow{3}{*}{ Calf } & Brain & $11.0 \%$ & $0.5 \%$ & $11.5 \%$ & $4.5 \%$ \\
\cline { 2 - 6 } & Kidney & $3.6 \%$ & $2.3 \%$ & $6.0 \%$ & $63.8 \%$ \\
\cline { 2 - 6 } & Liver & $3.5 \%$ & $1.4 \%$ & $5.0 \%$ & $40.4 \%$ \\
\hline \multirow{3}{*}{ Goat } & Brain & $12.3 \%$ & $0.6 \%$ & $13.0 \%$ & $5.2 \%$ \\
\cline { 2 - 6 } & Kidney & $3.5 \%$ & $1.7 \%$ & $5.2 \%$ & $48.2 \%$ \\
\cline { 2 - 6 } & Liver & $4.1 \%$ & $1.9 \%$ & $6.0 \%$ & $45.3 \%$ \\
\hline
\end{tabular}




\section{PEth concentration of tissue samples}

\section{Brain}

For the calf and pig brain, a saturation curve for PEth formation could be observed, see Figure 3. A Lineweaver-Burk plot revealed a $\mathrm{V}_{\max }$ of $0.67 \mu \mathrm{mol}^{*} \mathrm{~h}^{-1 *} \mathrm{~kg}^{-1}$ with a $\mathrm{K}_{\mathrm{m}}$ of $1.74 \mathrm{~g} / \mathrm{kg}$ (calf), and a $\mathrm{V}_{\max }$ of $1.38 \mu \mathrm{mol}^{*} \mathrm{~h}^{-1 *} \mathrm{~kg}^{-1}$ with a $\mathrm{K}_{\mathrm{m}}$ of $5.20 \mathrm{~g} / \mathrm{kg}$ (pig) for the formation of PEth 16:0/18:1. For the formation of PEth 16:0/18:2, a $\mathrm{V}_{\max }$ of $0.023 \mu \mathrm{mol} * \mathrm{~h}^{-}$ ${ }^{1} \mathrm{~kg}^{-1}$ with a $\mathrm{K}_{\mathrm{m}}$ of $0.90 \mathrm{~g} / \mathrm{kg}$ (calf), and a $\mathrm{V}_{\max }$ of $0.044 \mu \mathrm{mol}^{*} \mathrm{~h}^{-1 *} \mathrm{~kg}^{-1}$ with a $\mathrm{K}_{\mathrm{m}}$ of $2.22 \mathrm{~g} / \mathrm{kg}$ (pig) was observed. Based on these results, the formation of PEth in calf brain appears to reach saturation at lower concentrations, when compared to the pig sample. The observed formation rates for PEth in goat brain tissue varied heavily from 5-7 g/kg, which did not result in an ambiguous saturation curve. Formation rates of up to $3 \mu \mathrm{mol}^{*} \mathrm{~h}^{-1 *} \mathrm{~kg}^{-1}$ for PEth 16:0/18:1 and up to $0.12 \mu \mathrm{mol}^{*} \mathrm{~h}^{-1 *} \mathrm{~kg}^{-1}$ for PEth 16:0/18:2 were observed in goat brain samples. The subsequent analysis of the second sample taken at every time point confirmed this observation. Observable for all brain samples was a large increase in PEth 16:0/18:1 over time, while PEth 16:0/18:2 was formed at a much lower rate (4.1-5.5\% PEth 16:0/18:2, when compared to PEth 16:0/18:1). This observation can be explained by observing about the same difference in substrate availability, see the section PC concentration in brain samples. For a detailed comparison please have a look at Table 4.
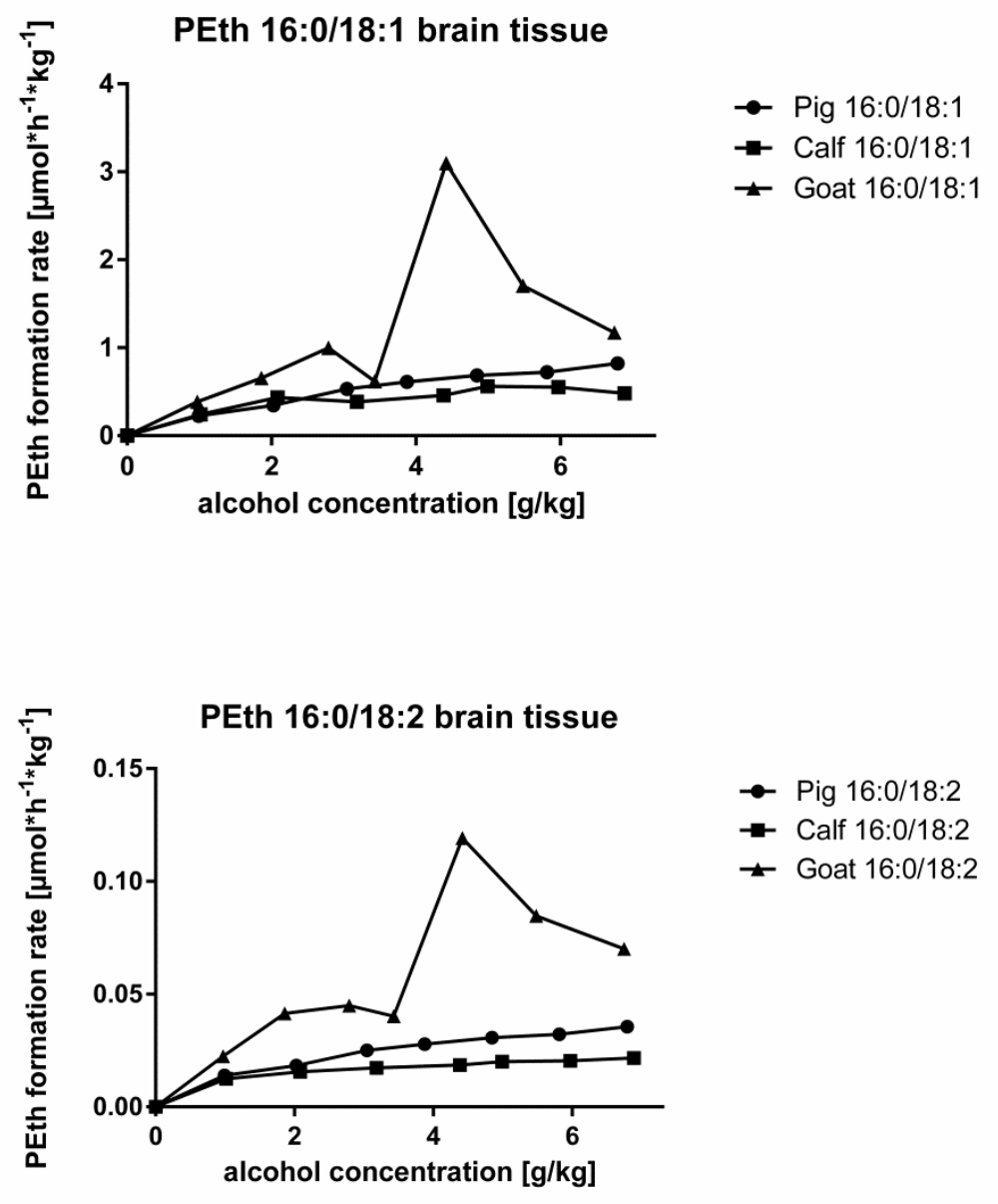

Figure 3 Formation rates of PEth 16:0/18:1 and PEth 16:0/18:2 in brain tissue from a goat, a pig, and a calf.

Liver 
For all PEth formation rates observed in the different liver tissue samples at different alcohol concentrations, a Lineweaver-Burk plot was performed, which resulted in the following formation rates for PEth 16:0/18:1: a $V_{\max }$ of $0.256 \mu \mathrm{mol}^{*} \mathrm{~h}^{-1 *} \mathrm{~kg}^{-1}$ with a $\mathrm{K}_{\mathrm{m}}$ of $2.96 \mathrm{~g} / \mathrm{kg}$ (goat), a $\mathrm{V}_{\max }$ of $0.316 \mu \mathrm{mol}^{*} \mathrm{~h}^{-1 *} \mathrm{~kg}^{-1}$ with a $\mathrm{K}_{\mathrm{m}}$ of $3.74 \mathrm{~g} / \mathrm{kg}$ (calf), and a $V_{\max }$ of $0.172 \mu \mathrm{mol}^{*} \mathrm{~h}^{-1 *} \mathrm{~kg}^{-1}$ with a $\mathrm{K}_{\mathrm{m}}$ of $5.63 \mathrm{~g} / \mathrm{kg}$ (pig), see Figure 4. For PEth 16:0/18:2 however, the following rates were observed: a $\mathrm{V}_{\max }$ of $0.102 \mu \mathrm{mol} * \mathrm{~h}^{-1 *} \mathrm{~kg}^{-1}$ with a $\mathrm{K}_{\mathrm{m}}$ of $2.18 \mathrm{~g} / \mathrm{kg}$ (goat), a $\mathrm{V}_{\max }$ of $0.097 \mu \mathrm{mol}^{*} \mathrm{~h}^{-1} \mathrm{~kg}^{-1}$ with a $\mathrm{K}_{\mathrm{m}}$ of $2.11 \mathrm{~g} / \mathrm{kg}$ (calf), and a $\mathrm{V}_{\max }$ of $0.143 \mu \mathrm{mol}^{*} \mathrm{~h}^{-1 *} \mathrm{~kg}^{-1}$ with a $\mathrm{K}_{\mathrm{m}}$ of $4.4 \mathrm{~g} / \mathrm{kg}$ (pig). The pig liver tissue seems to have a lower formation rate for PEth. With respect to PEth 16:0/18:2 this seems to be compensated by about twice the amount of the relative PC substrate within the tissue, resulting in about the same formation rate as goat or calf tissue, see the section PC concentration in liver samples. For a detailed comparison please have a look at Table 4.
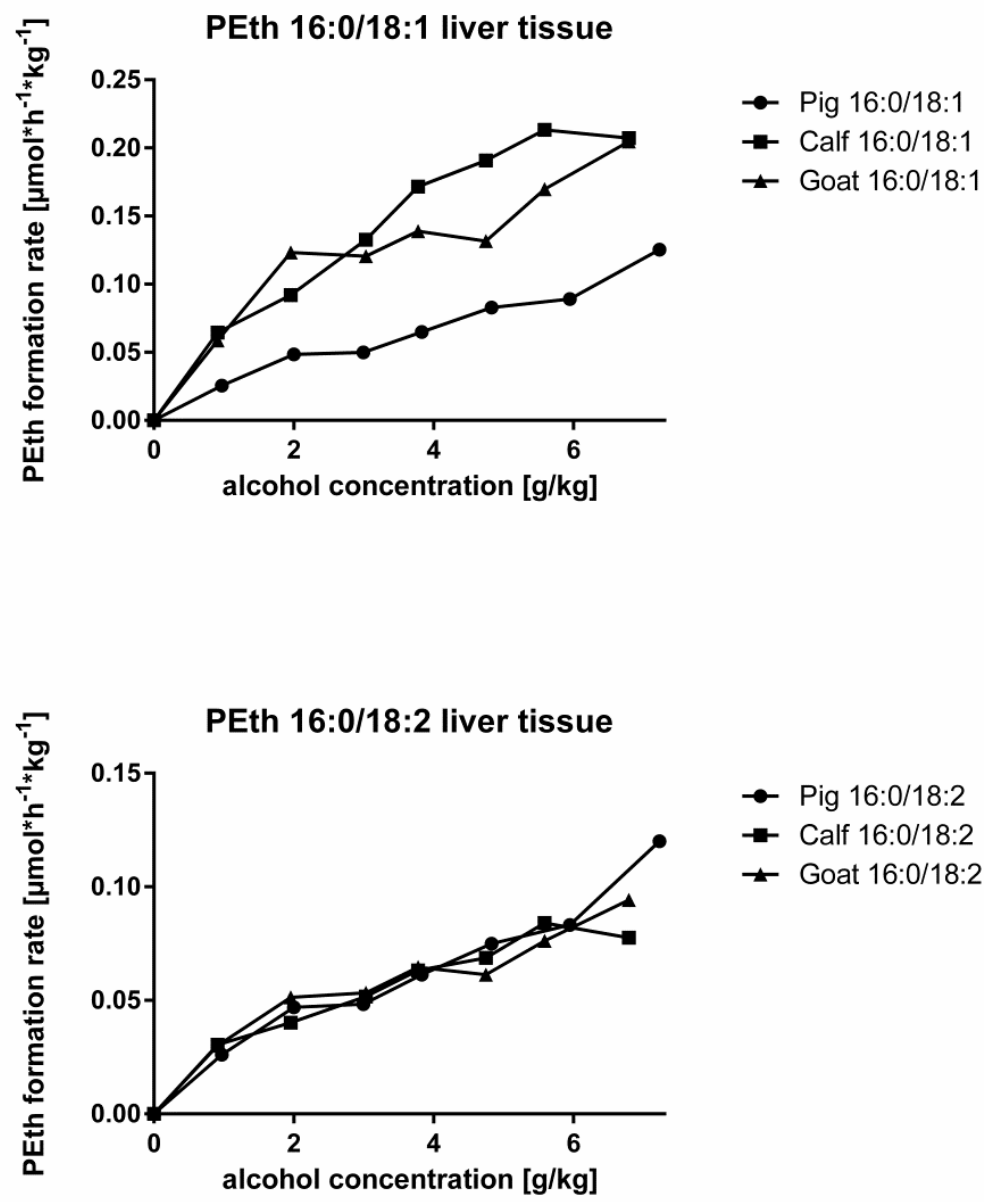

Figure 4 Formation rates of PEth 16:0/18:1 and PEth 16:0/18:2 in liver tissue from a goat, a pig, and a calf. 


\section{Kidney}

The observed formation rates for kidney tissue in samples from goat and calf were similar, this resulted in a Lineweaver-Burk plot with the following results: $V_{\max }$ of $1.25 \mu \mathrm{mol}^{*} \mathrm{~h}^{-1} * \mathrm{~kg}^{-1}$ with a $\mathrm{K}_{\mathrm{m}}$ of $5.74 \mathrm{~g} / \mathrm{kg}$ (calf), $\mathrm{V}_{\max }$ of $1.18 \mu \mathrm{mol}^{*} \mathrm{~h}^{-1 *} \mathrm{~kg}^{-1}$ with a $\mathrm{K}_{\mathrm{m}}$ of $6.0 \mathrm{~g} / \mathrm{kg}$ (goat) for PEth 16:0/18:1, see Figure 5. For PEth 16:0/18:2 a $\mathrm{V}_{\max }$ of 0.96 $\mu \mathrm{mol}^{*} \mathrm{~h}^{-1 *} \mathrm{~kg}^{-1}$ with a $\mathrm{K}_{\mathrm{m}}$ of $5.60 \mathrm{~g} / \mathrm{kg}$ (calf) and a $\mathrm{V}_{\max }$ of $0.92 \mu \mathrm{mol} * \mathrm{~h}^{-1 *} \mathrm{~kg}^{-1}$ with a $\mathrm{K}_{\mathrm{m}}$ of $6.90 \mathrm{~g} / \mathrm{kg}$ (goat) was observed. The pig kidney, however, showed lower rates, with a $V_{\max }$ of $0.318 \mu \mathrm{mol}^{*} \mathrm{~h}^{-1 *} \mathrm{~kg}^{-1}$ with a $\mathrm{K}_{\mathrm{m}}$ of $4.4 \mathrm{~g} / \mathrm{kg}$ (pig) for PEth 16:0/18:1 and $\mathrm{V}_{\max }$ of $0.36 \mu \mathrm{mol}^{*} \mathrm{~h}^{-1 *} \mathrm{~kg}^{-1}$ with a $\mathrm{K}_{\mathrm{m}}$ of $5.6 \mathrm{~g} / \mathrm{kg}$ (pig) for PEth 16:0/18:2. For a detailed comparison please have a look at Table 4.
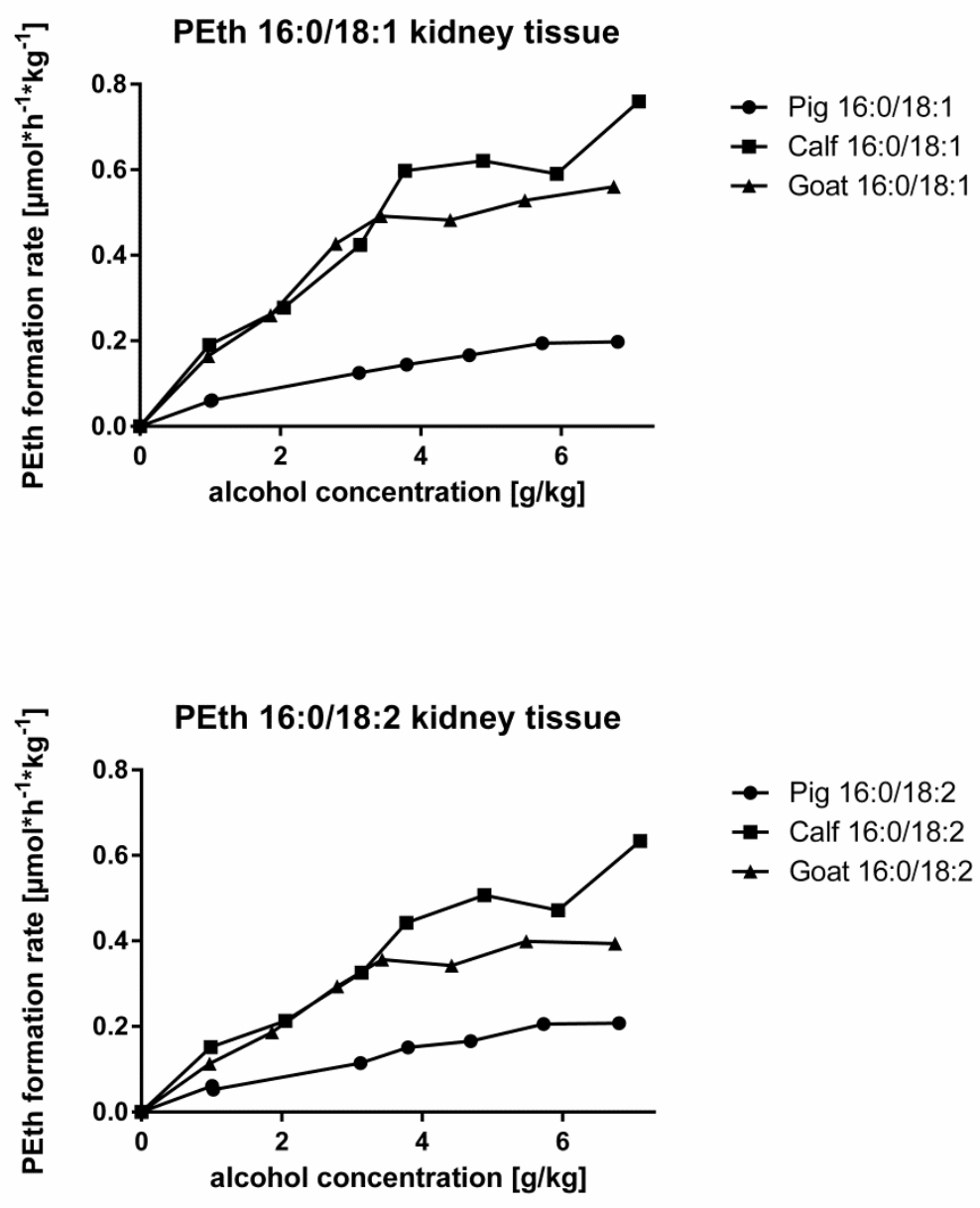

Figure 5 Formation rates of PEth 16:0/18:1 and PEth 16:0/18:2 in kidney tissue from a goat, a pig, and a calf. 
Table 4 Kinetic parameters obtained for Peth 16:0/18:1 and PEth 16:0/18:2 in the course of this study.

\begin{tabular}{|c|c|c|c|c|c|c|}
\hline & & \multicolumn{2}{|c|}{ PEth 16:0/18:1 } & \multicolumn{2}{|c|}{ PEth 16:0/18:2 } & \multirow[b]{2}{*}{$\begin{array}{c}\text { Ratio } V_{\max } \\
V_{\max }(16: 0 / 18: 2) / V_{\max }(16: 0 / 18: 1)\end{array}$} \\
\hline & & $\begin{array}{c}\mathbf{V}_{\max } \\
\mu \mathrm{mol}^{*} \mathrm{~h}^{-1} * \mathrm{~kg}^{-1}\end{array}$ & $\begin{array}{l}\mathbf{K}_{\mathbf{m}} \\
\mathrm{g} / \mathrm{kg}\end{array}$ & $\begin{array}{c}\mathbf{V}_{\max } \\
\mu \mathrm{mol}^{*} \mathrm{~h}^{-} \\
1 * \mathrm{~kg}^{-1}\end{array}$ & $\begin{array}{l}\mathbf{K}_{\mathbf{m}} \\
\mathrm{g} / \mathrm{kg}\end{array}$ & \\
\hline \multirow{3}{*}{ Pig } & Brain & 1.38 & 5.20 & 0.044 & 2.22 & $3 \%$ \\
\hline & Kidney & 0.318 & 4.4 & 0.36 & 5.6 & $113 \%$ \\
\hline & Liver & 0.172 & 5.63 & 0.143 & 4.4 & $83 \%$ \\
\hline \multirow{3}{*}{ Calf } & Brain & 0.67 & 1.74 & 0.023 & 0.9 & $3 \%$ \\
\hline & Kidney & 1.25 & 5.74 & 0.96 & 5.60 & $77 \%$ \\
\hline & Liver & 0.316 & 3.74 & 0.097 & 2.11 & $31 \%$ \\
\hline \multirow{3}{*}{ Goat } & Brain & \multicolumn{5}{|c|}{ No reliable data } \\
\hline & Kidney & 1.18 & 6.0 & 0.92 & 6.90 & $78 \%$ \\
\hline & Liver & 0.256 & 2.96 & 0.102 & 2.18 & $40 \%$ \\
\hline
\end{tabular}




\section{Blood}

The formation of PEth in blood from pig and calf remained below the limit of quantitation, supporting the observation of Viel et al. that human red blood cells seem to be peculiar in forming PEth in-vitro in the presence of ethanol (24).

\section{Comparison between PC and PEth composition and the ratio of $V_{\max }$}

A comparison between the measured PC 16:0/18:2 to PC 16:0/18:1 ratio and the measured PEth 16:0/18:2 to PEth 16:0/18:1 ratio indicates a relationship between substrate availability and product formation, see Figure 6 . Especially for all the brain samples, as well as calf liver and goat liver, the substrate ratio closely reflects the observed PEth ratio (differences of 0-3\%). Pig liver showed a higher difference (15\%). For kidney samples, larger discrepancies were measured for all animal species (differences of 14-21\%). Based on this observation, the formation of PEth in kidney tissue could be influenced by other factors than just substrate availability.

Comparing the ratio between the measured PEth 16:0/18:2 and PEth 16:0/18:1 concentration with the ratio obtained for maximum velocity between PEth 16:0/18:2 and PEth 16:0/18:1, we can see that there is a strong link between the directly observable PEth ratio and the obtained kinetic parameters.

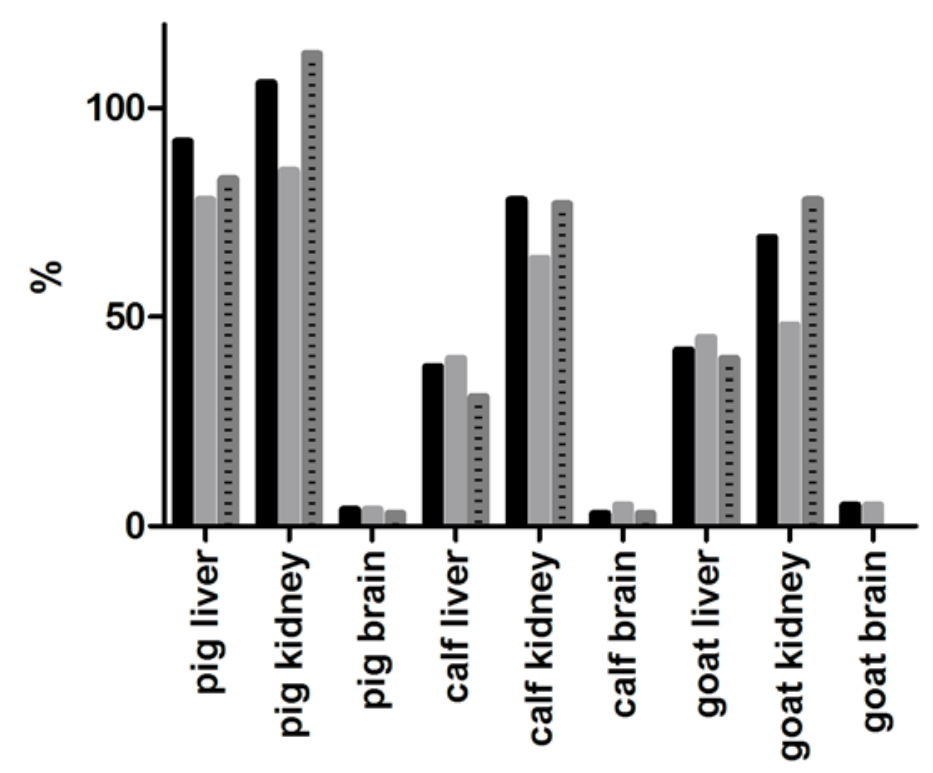
$\square$ PEth ratio (16:0/18:2) / $(16: 0 / 18: 1)$
PC ratio (16:0/18:2) / $(16: 0 / 18: 1)$
= V $\max$ ratio (16:0/18:2) / (16:0/ 18:1)

Figure 6 Comparison between the PC ratio ((16:0/18:2)/(16:0/18:1)), the PEth ratio ((16:0/18:2)/(16:0/18:1)), and the $V_{\max }$ ratio ((16:0/18:2)/(16:0/18:1)) in the different animal tissue samples. For the PEth ratio, the mean of the observed ratios for all series ( 1 to $7 \mathrm{~g} / \mathrm{kg}$ of ethanol) after 5 hours incubation time is represented. 


\section{Isomer specific fragment ion abundances of PEth}

Contrary to spiked quality control samples in tissue, produced with the same PEth solutions as the calibration curves, samples containing PEth produced by in-vitro formation from endogenous PC showed differences in the quantification results when quantifying with either SRM1 or SRM2 as the only quantifier. We therefore decided to report the PEth concentrations as the mean concentration of both SRM transitions as final concentration throughout the manuscript (previously mentioned in the material and methods section). Especially brain samples show elevated ratios from 126-138\%. Detailed information about the differences in ratios obtained in tissue samples is displayed in Table 5 (PEth 16:0/18:1).

Caution has to be taken with the interpretation of this data, as the observed ratio is dependent on the composition (positional isomer distribution) of the reference solution used for the generation of the calibration. Reference solutions from a different manufacturer might lead to different ratios.

Table 5 The concentration determined with the SRM transition which monitors SRM1 (product ion with $\mathbf{m} / \mathbf{z}$ 255 (palmitate (16:0)) was divided by the quantitative result with SRM 2 (product ion with $\mathrm{m} / \mathrm{z} 281.3$ (oleate (18:1)) or 279.4 (linoleate (18:2))). The here presented data shows the ratio.

\begin{tabular}{|c|c|c|c|}
\hline & Brain & Liver & Kidney \\
\hline Calf & $135 \%$ & $104 \%$ & $102 \%$ \\
\hline Goat & $138 \%$ & $117 \%$ & $119 \%$ \\
\hline Pig & $126 \%$ & $119 \%$ & $136 \%$ \\
\hline $\begin{array}{c}\text { Human blood (spiked } \\
\text { QC from validation) }\end{array}$ & $100 \%$ \\
\hline
\end{tabular}

\section{Conclusion}

The simultaneous measurement of PC and PEth provides additional information, as the substrate concentration (PC) influences the formation of the product (PEth). This can help to explain differences in PEth concentrations between various tissues. For example the observation of Thompson et al., that PEth 16:0/18:1 levels were about 10-fold higher than PEth 16:0/18:2 in all subjects and both areas of human brain (cerebellum and orbital frontal cortex), is very likely based on a PC ratio within the human brain which is similar to the PC distributions observed in this study for goat, pig, and calf brain (10). Considering the significance of the results, it should be kept in mind, that only one individual of each species was investigated during this study.

By having low concentrations of PC within the sample, the newly developed method is able to determine the analytes, PC and PEth, within one run, making it an ideal tool to assess PC and PEth distributions within the blood. This may find an application in the study of communities with different nutritional habits. A disadvantage for the accuracy of PC determination is however the omnipresence of PC within biological samples. To address this issue, a solvent based calibration is required, which does not account for potential matrix effects.

Considering the formation of PEth, the presented methodology was able to show increasing PEth formation rates with increasing ethanol concentrations in eight out of nine cases. The sample homogeneity when working with tissue samples appeared to be a crucial issue, as high variation in PEth formation rates were observed in goat brain, which was the smallest brain observed in this study. The need for a large amount of sample from a single, small organ appeared to be challenging. We therefore recommend the use of animals with larger organs for the investigation of in-vitro formation, as it is easier to obtain large amounts of specific samples (e.g. cerebral cortex). Furthermore, we recommend the analysis of several samples from different organs when performing PEth determination in postmortem samples. In our case, $V_{\max }$ and $\mathrm{K}_{\mathrm{m}}$ values evaluated by Michaelis-Menten kinetics showed a large variation between different organs and different species. If these differences are caused by different PLD isoforms or just varying PLD concentrations within the tissue remains unknown. Different isozymes of PLD, which could be responsible for this observation, have been identified and an organ-specific distribution of PLD isozymes was 
demonstrated by earlier investigations (25-27). with respect to this issue, the group of Arradotir et al. investigated rat organs after ethanol exposure and stated that variations in PEth levels, the rate of PEth formation, and the PEth degradation are organ specific, which is supported by our findings (19). To prevent the post sampling formation of PEth in organ tissue observed by Arradotir et al., we recommend immediate homogenization and subsequent storage in a solvent such as acetonitrile, to precipitate any PLD (9). Additionally, we recommend the inclusion of transitions for both fatty acid chains within the method to observe and correct isomer specific fragment ion abundances. 


\section{Acknowledgements}

We would like to thank the team of the Forensic Toxicology and Chemistry Laboratory of the Institute of Forensic Medicine Bern for their support during this study.

\section{Conflict of Interest}

The authors declare that they have no conflict of interest.

\section{Compliance with Ethical Standards}

The animal tissues investigated during this study were freshly obtained from slaughtered animals. As the animals were butchered for meat production, the killing or any potential suffering of the animal is not related to the presented study. Blood samples, as any other tissue were collected when the animals were already dead. 


\section{References}

1. Schröck A, Thierauf A, Wurst FM, Thon N, Weinmann W. Progress in monitoring alcohol consumption and alcohol abuse by phosphatidylethanol. Bioanalysis. 2014;6(17):2285-94.

2. Wurst FM, Thon N, Weinmann W, Yegles M, Preuss UW. Biological State Marker for Alcohol Consumption. In: el-Guebaly N, Carrà G, Galanter M, editors. Textbook of Addiction Treatment: International Perspectives. Milano: Springer Milan; 2015. p. 261-92.

3. Luginbühl M, König S, Schürch $\mathrm{S}$, Weinmann W. Evaluation of $\mathrm{N}$-acetyltaurine as an ethanol marker in human blood. Manuscript accepted by Alcohol in May 2017.

4. Luginbühl M, Schröck A, König $S$, Schürch $S$, Weinmann W. Determination of fatty acid ethyl esters in dried blood spots by LC-MS/MS as markers for ethanol intake: application in a drinking study. Anal Bioanal Chem. 2016;408(13):3503-9.

5. Gnann H, Thierauf A, Hagenbuch F, Rohr B, Weinmann W. Time dependence of elimination of different PEth homologues in alcoholics in comparison with social drinkers. Alcoholism, clinical and experimental research. 2014 Feb;38(2):322-6. PubMed PMID: 24471840. Epub 2014/01/30. eng.

6. Dresen S, Weinmann W, Wurst FM. Forensic confirmatory analysis of ethyl sulfate--a new marker for alcohol consumption--by liquid-chromatography/electrospray ionization/tandem mass spectrometry. Journal of the American Society for Mass Spectrometry. 2004 Nov;15(11):1644-8. PubMed PMID: 15519232. Epub 2004/11/03. eng.

7. Luginbühl M, Rutjens S, König S, Furrer J, Weinmann W. N-Acetyltaurine as a novel urinary ethanol marker in a drinking study. Analytical and Bioanalytical Chemistry. 2016:1-8.

8. Luginbühl M, Nussbaumer S, Weinmann W. Decrease of ethyl glucuronide concentrations in hair after exposure to chlorinated swimming pool water. Drug testing and analysis.n/a-n/a.

9. Aradottir S, Seidl S, Wurst FM, Jonsson BA, Alling C. Phosphatidylethanol in human organs and blood: a study on autopsy material and influences by storage conditions. Alcoholism, clinical and experimental research. 2004 Nov;28(11):1718-23. PubMed PMID: 15547459. Epub 2004/11/18. eng. 10. Thompson PM, Hill-Kapturczak N, Lopez-Cruzan M, Alvarado LA, Dwivedi AK, Javors MA. Phosphatidylethanol in Postmortem Brain and Serum Ethanol at Time of Death. Alcoholism: Clinical and Experimental Research. 2016;40(12):2557-62.

11. Faller A, Richter B, Kluge M, Koenig P, Seitz HK, Skopp G. Stability of phosphatidylethanol species in spiked and authentic whole blood and matching dried blood spots. International journal of legal medicine. 2013 May 01;127(3):603-10.

12. Steed PM, Clark KL, Boyar WC, Lasala DJ. Characterization of human PLD2 and the analysis of PLD isoform splice variants. FASEB journal : official publication of the Federation of American Societies for Experimental Biology. 1998 Oct;12(13):1309-17. PubMed PMID: 9761774. Epub 1998/10/08. eng.

13. Lehmann WD, Wozny K, Brügger B. Spotting of Structural Isomer Mixtures of DiacylGlycerophospholipids via UPLC-MS/MS. DGMS meeting Kiel 2017.

14. Alexandra Schröck AH, Peter Bütikofer, Stefan König, Wolfgang Weinmann Standardization of an enzyme activity test for phospholipase $D(P L D)$ in blood and test of two selective PLD inhibitors submitted for publication to FSI. 2016.

15. Weinmann W, Schrock A, Wurst FM. Commentary on the Paper of Walther L. et al.: Phosphatidylethanol is Superior to CDT and GGT as an Alcohol Marker and Is a Reliable Estimate of Alcohol Consumption Level. Alcoholism, clinical and experimental research. 2016 Feb;40(2):260-2. PubMed PMID: 26833179. Epub 2016/02/03. eng.

16. Svensson BG, Akesson B, Nilsson A, Skerfving S. Fatty acid composition of serum phosphatidylcholine in healthy subjects consuming varying amounts of fish. European journal of clinical nutrition. 1993 Feb;47(2):132-40. PubMed PMID: 8436091. Epub 1993/02/01. eng. 
17. Kostetskii E, Gerasimenko NI, Kushnerova NF. [The phospholipid composition of organs and tissues of rabbit]. Biokhimiia (Moscow, Russia). 1977 Apr;42(4):672-6. PubMed PMID: 870088. Epub 1977/04/01. rus.

18. Aradottir S, Moller K, Alling C. Phosphatidylethanol formation and degradation in human and rat blood. Alcohol Alcohol. 2004 Jan-Feb;39(1):8-13. PubMed PMID: 14691067. Epub 2003/12/24. eng. 19. Aradottir S, Lundqvist $C$, Alling C. Phosphatidylethanol in rat organs after ethanol exposure. Alcoholism, clinical and experimental research. 2002 Apr;26(4):514-8. PubMed PMID: 11981128. Epub 2002/05/01. eng.

20. Schröck A, Hernández Redondo A, Martin Fabritius M, König S, Weinmann W.

Phosphatidylethanol (PEth) in blood samples from "driving under the influence" cases as indicator for prolonged excessive alcohol consumption. International journal of legal medicine. 2016;130(2):393-400.

21. Matuszewski BK, Constanzer ML, Chavez-Eng CM. Strategies for the assessment of matrix effect in quantitative bioanalytical methods based on HPLC-MS/MS. Analytical chemistry. $2003 \mathrm{Jul}$ 1;75(13):3019-30. PubMed PMID: 12964746. Epub 2003/09/11. eng.

22. Aderjan R. ea. Richtlinien zur Bestimmung der Blutalkoholkonzentration (BAK) für forensische Zwecke. 2011;48:137-43.

23. FDA UDoHaHS. Guidance for industry: bioanalytical method validation. 2001.

24. Viel G, Boscolo-Berto R, Cecchetto G, Fais P, Nalesso A, Ferrara SD. Phosphatidylethanol in Blood as a Marker of Chronic Alcohol Use: A Systematic Review and Meta-Analysis. International Journal of Molecular Sciences. 2012;13(11):14788-812. PubMed PMID: 23203094.

25. Katayama K, Kodaki T, Nagamachi Y, Yamashita S. Cloning, differential regulation and tissue distribution of alternatively spliced isoforms of ADP-ribosylation-factor-dependent phospholipase D from rat liver. The Biochemical journal. 1998 Feb 01;329 ( Pt 3):647-52. PubMed PMID: 9445394. Pubmed Central PMCID: PMC1219088. Epub 1998/03/07. eng.

26. Kodaki T, Yamashita S. Cloning, expression, and characterization of a novel phospholipase D complementary DNA from rat brain. The Journal of biological chemistry. 1997 Apr 25;272(17):11408-13. PubMed PMID: 9111050. Epub 1997/04/25. eng.

27. Colley WC, Sung TC, Roll R, Jenco J, Hammond SM, Altshuller Y, et al. Phospholipase D2, a distinct phospholipase $D$ isoform with novel regulatory properties that provokes cytoskeletal reorganization. Current biology : CB. 1997 Mar 01;7(3):191-201. PubMed PMID: 9395408. Epub 1997/03/01. eng. 
Table 6 recovery, extraction efficiency, matrix effect for the investigated tissue samples, investigated at a low and high PEth concentration $(0.15 \mu \mathrm{g} / \mathrm{g}$ and $1.5 \mu \mathrm{g} / \mathrm{g})$. The data represents the mean of SRM1 and SRM2, by taking the mean out of three measurements at each concentration, in each tissue.

\begin{tabular}{|c|c|c|c|c|c|c|c|}
\hline & & \multicolumn{2}{|c|}{ recovery } & \multicolumn{2}{|c|}{ extraction efficiency } & \multicolumn{2}{|c|}{ matrix effect } \\
\hline & & PEth 16:0/18:1 & PEth 16:0/18:2 & PEth 16:0/18:1 & PEth 16:0/18:2 & PEth 16:0/18:1 & PEth 16:0/18:2 \\
\hline \multirow{6}{*}{ pig } & liver low & $91 \%$ & $93 \%$ & $86 \%$ & $85 \%$ & $106 \%$ & $109 \%$ \\
\hline & liver high & $75 \%$ & $78 \%$ & $78 \%$ & $84 \%$ & $96 \%$ & $93 \%$ \\
\hline & kidney low & $108 \%$ & $111 \%$ & $95 \%$ & $92 \%$ & $113 \%$ & $121 \%$ \\
\hline & kidney high & $84 \%$ & $90 \%$ & $86 \%$ & $93 \%$ & $97 \%$ & $97 \%$ \\
\hline & brain low & $118 \%$ & $94 \%$ & $92 \%$ & $83 \%$ & $130 \%$ & $114 \%$ \\
\hline & brain high & $63 \%$ & $71 \%$ & $72 \%$ & $79 \%$ & $87 \%$ & $90 \%$ \\
\hline \multirow{6}{*}{ calf } & liver low & $84 \%$ & $99 \%$ & $76 \%$ & $86 \%$ & $111 \%$ & $116 \%$ \\
\hline & liver high & $76 \%$ & $84 \%$ & $80 \%$ & $85 \%$ & $95 \%$ & $98 \%$ \\
\hline & kidney low & $86 \%$ & $104 \%$ & $83 \%$ & $84 \%$ & $103 \%$ & $123 \%$ \\
\hline & kidney high & $79 \%$ & $89 \%$ & $80 \%$ & $87 \%$ & $100 \%$ & $102 \%$ \\
\hline & brain low & $106 \%$ & $98 \%$ & $83 \%$ & $91 \%$ & $127 \%$ & $108 \%$ \\
\hline & brain high & $64 \%$ & $78 \%$ & $67 \%$ & $82 \%$ & $96 \%$ & $95 \%$ \\
\hline \multirow{6}{*}{ goat } & liver low & $84 \%$ & $101 \%$ & $78 \%$ & $89 \%$ & $109 \%$ & $113 \%$ \\
\hline & liver high & $74 \%$ & $80 \%$ & $76 \%$ & $83 \%$ & $97 \%$ & $96 \%$ \\
\hline & kidney low & $115 \%$ & $118 \%$ & $86 \%$ & $99 \%$ & $132 \%$ & $119 \%$ \\
\hline & kidney high & $73 \%$ & $82 \%$ & $74 \%$ & $83 \%$ & $99 \%$ & $99 \%$ \\
\hline & brain low & $116 \%$ & $108 \%$ & $83 \%$ & $98 \%$ & $140 \%$ & $110 \%$ \\
\hline & brain high & $65 \%$ & $74 \%$ & $71 \%$ & $80 \%$ & $92 \%$ & $93 \%$ \\
\hline
\end{tabular}

